\title{
Perioperative Challenges in an Infant with Uncorrected "Pink-Tetralogy of Fallot"-for Excision of Choroid Plexus Papilloma: A Case Report
}

\author{
Julia Pearl ${ }^{1} \quad$ Karen Ruby Lionel ${ }^{1} \quad$ Ramamani Mariappan $^{1}$
}

${ }^{1}$ Department of Anaesthesia, Christian Medical College, Vellore, Tamil Nadu, India
Address for correspondence Ramamani Mariappan, DA, MD, DNB, Department of Anaesthesia, Christian Medical College, Vellore 632004, Tamil Nadu, India (e-mail: ramamani@cmcvellore.ac.in).

J Neuroanaesthesiol Crit Care 2018;5:114-116.
Abstract
Keywords
- infant
- choroid plexus papilloma
- craniotomy
- tetralogy of Fallot

Perioperative management of an infant with intracranial tumor and congenital cyanotic heart disease poses a lot of challenges to the neuroanesthesiologist and neurointensivist. Maintaining both the cardiovascular and cerebrovascular homeostasis are of paramount importance for a successful outcome. In this case report, we have mentioned the perioperative challenges of a 7-month-old baby with tetralogy of Fallot who underwent craniotomy and excision of choroid plexus papilloma.

\section{Introduction}

Perioperative management of an infant with intracranial lesion and underlying cyanotic congenital heart disease (CHD) poses unique challenges to the neuroanesthesiologist and neurointensivist because of their complex hemodynamics. While managing these cases, both cardiovascular and cerebrovascular homeostasis have to be maintained for a successful outcome. An infant with CHD coming for noncardiac surgery is a common event. ${ }^{1-3}$ Children with cyanotic heart diseases such as tetralogy of Fallot (TOF) coming for stereotactic aspiration or craniotomy for abscess drainage have also been reported commonly. ${ }^{4,5}$ However, an infant with TOF coming for craniotomy and excision of an intraventricular tumor is an uncommon event. Here we report the anesthetic challenges of an infant with TOF coming for craniotomy and excision of a choroid plexus papilloma.

\section{Case Report}

A 7-month-old male child (weight $7 \mathrm{~kg}$, height $68 \mathrm{~cm}$ ) was admitted with the diagnosis of choroid plexus papilloma for craniotomy and excision of the tumor. At 3 months of age, he was diagnosed with TOF with a bidirectional shunt. There was a history of sweating and difficulty in continuous sucking during breast-feeding. However, there was no history of cyanosis, cyanotic spells, or recurrent upper or lower respiratory tract infection. All developmental milestones were achieved according to age till date.

At 4 months of age, the patient had multiple episodes of tonic posturing associated with vomiting and irritable cry. He was evaluated and found to have a choroid plexus papilloma with hydrocephalus for which right ventriculoperitoneal shunt was done and the child improved symptomatically.

On examination, the child was alert and active, and his head circumference was $42 \mathrm{~cm}$, anterior fontanelle was lax and sunken, and shunt site was healthy. He had posterior plagiocephaly (positional). There was no focal neurological deficit. Airway examination appeared normal, and there were no other congenital anomalies or dysmorphic facial features. His heart rate was 112 beats/min, and the respiratory rate was 40 breaths/min with the saturation of 98 to $99 \%$. Cardiovascular examination revealed pansystolic murmur in the pulmonary area radiating all over the precordium. Respiratory and abdominal examinations were within normal limits.

His blood investigations were within normal limits with the hemoglobin of $11 \mathrm{~g} / \mathrm{dL}$. Magnetic resonance imaging (MRI) of the brain with contrast showed a well-defined large lobulated frond-like mass filling the atrium of right lateral ventricle measuring approximately $4.0 \times 3.3 \times 1.4 \mathrm{~cm}$ with hydrocephalus ( - Fig. 1). The mass was hypointense on T1W sequences and hyperintense on $\mathrm{T} 2 \mathrm{~W}$ sequences with marked received

March 23, 2018

accepted

May 14, 2018

published online

June 03, 2018
DOI https://doi.org/

$10.1055 / \mathrm{s}-0038-1660692$

ISSN 2348-0548.
Copyright $\odot 2018$ Indian Society of Neuroanaesthesiology and Critical Care
License terms

() (1) $\ominus \circledast$ 


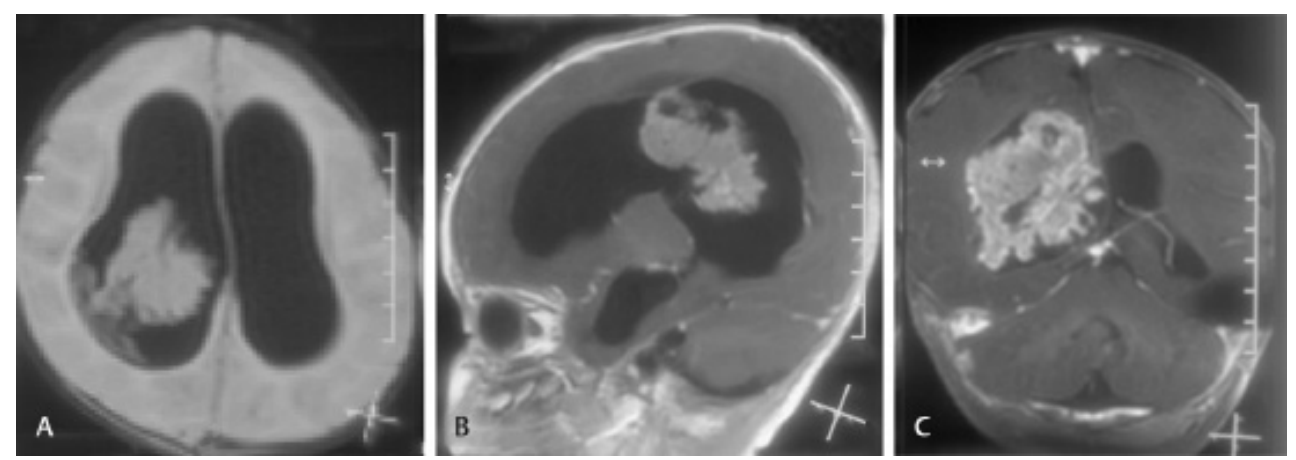

Fig. 1 (A-C) T1W postcontrast images of MRI of brain showing a large well-defined mass in the right atrium with hydrocephalus. MRI, magnetic resonance imaging.

enhancement on contrast administration. Electrocardiogram (ECG) showed sinus rhythm, right ventricular hypertrophy, and right axis deviation. Echocardiography revealed TOF with the components of subaortic ventricular septal defect (VSD, 9 $\mathrm{mm}$ ) with a bidirectional shunt, severe infundibular valvular stenosis with doming of pulmonary valve seen, and less than $50 \%$ overriding of the aorta with an ejection fraction of $55 \%$.

A multidisciplinary team involving the neurosurgeon, cardiologist, and neuroanesthesiologist was consulted regarding the management, and it was decided to proceed with craniotomy and excision because of the large tumor size and its enhancement. The TOF correction was planned after the age of 1 year. An informed consent was taken from the parents after explaining the risks of perioperative cardiac morbidity and requirement of massive transfusion and its associated complications and the need for postoperative ventilation.

It is our routine practice to achieve intravenous access, a night before surgery, to prevent dehydration in these cases. Because the child had difficult intravenous access, it was decided not to start an intravenous line in the ward to avoid sympathetic stimulation. Hydration was continued by oral means till 2 hours prior to surgery. Syrup levetiracetam 60 $\mathrm{mg}$ and phenytoin $15 \mathrm{mg}$ twice daily were continued preoperatively. Because the child had a functioning ventriculoperitoneal (VP) shunt, we decided to sedate the child with syrup trichloryl ( $80 \mathrm{mg} / \mathrm{kg}$ ) for 45 minutes prior to arrival to operating room. The operating room was ready with necessary drugs, equipment, and warm fluids.

The child was asleep on arrival to the operating room and was induced with sevoflurane (maximum up to $4 \%$ increase) and oxygen after connecting the pulse oximetry. Once the child was deep, all standard monitors were connected and a $24 \mathrm{G}$ intravenous line was started. Five milligrams of ketamine, $15 \mu \mathrm{g}$ of fentanyl, and $5 \mathrm{mg}$ of propofol were given, and the concentration of sevoflurane was reduced to $2 \%$. The child was paralyzed with $4 \mathrm{mg}$ of atracurium, intubated with 4.5-size uncuffed endotracheal tube (ETT), and was fixed at $12 \mathrm{~cm}$ at the lips. Anesthesia was maintained with air, oxygen, and sevoflurane (minimum alveolar concentration [MAC] 0.8-1) and an atracurium infusion $(5-10 \mu \mathrm{g} / \mathrm{kg} /$ min) that was titrated to achieve two twitches on train of four. The arterial $\mathrm{CO}_{2}\left(\mathrm{PaCO}_{2}\right)$ was maintained between 33 and $35 \mathrm{~mm} \mathrm{Hg}$. A 24-g arterial line was inserted into the left radial artery, and right subclavian 5.5F triple lumen central venous catheter was placed. Nasopharyngeal temperature, urine output, and sugar were monitored intraoperatively. Measures were taken to avoid air bubble entering into the venous system that can be shunted to the arterial system. Scalp block was given on the side of surgery with $6 \mathrm{~mL}$ of $0.2 \%$ bupivacaine, after which the child was positioned in the right lateral position for good surgical exposure. All pressure points were padded, and the child was warmed with forced hot air warming device 3M Bair hugger (Eden Prairie, Minnesota, United States). Ceftriaxone $50 \mathrm{mg} / \mathrm{kg}$ was given for both, infective endocarditis and surgical prophylaxis. To reduce the brain edema, $0.75 \mathrm{~g} / \mathrm{kg}$ of mannitol and $1 \mathrm{mg}$ of dexamethasone were given. Ringer's lactate was given as maintenance fluid. Intermittent doses of fentanyl up to $8 \mu \mathrm{g} / \mathrm{kg}$ and $0.75 \mathrm{mg}$ of morphine and $20 \mathrm{mg} / \mathrm{kg}$ of paracetamol were given for analgesia. Intraoperative mean blood pressure (BP) was maintained between 55 and $60 \mathrm{~mm} \mathrm{Hg}$. Low dose of noradrenaline was given $(0.02-0.05 \mu \mathrm{g} / \mathrm{kg} / \mathrm{min})$ to maintain the systemic vascular resistance (SVR) and to keep the BP within normal limit in times of surgical bleeding while resuscitating with fluid and blood. Because the tumor was big and vascular, the child had lost approximately $200 \mathrm{~mL}$ of blood that was replaced with $150 \mathrm{~mL}$ of red cells and $40 \mathrm{~mL}$ of colloid (130/0.4 volulyte). The rest $25 \mathrm{~mL}$ of blood was given slowly in the NICU to replace the blood loss in the drain. The surgery lasted for 4 hours. At the end of the procedure, repeat scalp block was given with $5 \mathrm{~mL}$ of $0.2 \%$ bupivacaine. The residual neuromuscular blockade was reversed with neostigmine and glycopyrrolate. Once the child started breathing comfortably with the respiratory rate of 30 breaths/min with good tidal volume and was awake, the ETT was removed. The child was shifted to neuro-ICU for postoperative monitoring. The postoperative hemoglobin was $10 \mathrm{~g} / \mathrm{dL}$.

\section{Discussion}

Tetralogy of Fallot is one of the common cyanotic CHDs, which accounts for approximately $10 \%$ of cyanotic heart diseases, and $50 \%$ infants with severe pulmonary stenosis die of hypoxia and congestive heart failure during 
the first year of life. Children with less severe pulmonary obstruction surviving this period later present with hypoxia, cyanosis, polycythemia, coagulopathies, congestive heart failure, and cyanotic spells. Children with mild pulmonary obstruction even survive to adulthood without any symptoms; they often referred to as "pink tetralogy of Fallot." ${ }^{6}$ TOF has four major components: right ventricular hypertrophy, overriding aorta, membranous ventricular septal defect, and right ventricular outflow tract obstruction. In our case, the child was considered as "pink tet" in which the degree of right ventricular outflow obstruction is minimal, resulting in minimal or no significant right-to-left shunt. Therefore, the child did not have hypoxia, cyanosis, or polycythemia during the preoperative period. Intraoperatively, measures were taken to avoid "tet spell" by maintaining the SVR using noradrenaline and by avoiding factors that can increase the pulmonary vascular resistance (PVR) (hypoxia, hypercarbia, and acidosis). Also, unlike adults (in whom only extreme hypoxia can lead to cerebral vasodilation), in infants even a minor degree of hypoxia can lead to an increase in cerebral blood flow and thereby the intracranial pressure (ICP) that can reduce the cerebral perfusion.

Maintaining the cerebral hemodynamics, while keeping the anesthetic goals of TOF in mind, is a tough challenge for an anesthesiologist, especially while managing a bleeding vascular tumor in a small infant. In our case, because the child had VP shunt and a difficult intravenous access, he was induced using sevoflurane and anesthesia was deepened with ketamine and propofol before intubation.

To provide brain relaxation for adequate surgical exposure and avoid undue pressure on the underlying brain by the surgical retractor, mannitol was given. Mannitol can cause osmotic diuresis, dehydration, and can lead to hypovolemia that can precipitate "tet spell." Fluids were titrated to keep the pulse pressure variation (PPV) less than 13, and the urine output was replaced adequately with Ringer's lactate. Blood loss was promptly replaced with red blood cells to avoid hypovolemia. A low dose of noradrenaline infusion was started to avoid acute hypovolemia in times of surgical bleeding and to maintain the SVR. We took measures to prevent intraoperative hypoxia, hypercarbia, acidosis, and hypothermia because these can precipitate a "tet spell." Scalp block was given before the surgical incision and before extubation to avoid the noxious stimulus-induced catecholamine release and to provide intra- as well as postoperative analgesia.

\section{Conclusion}

Thorough understanding of patient's complex cardiovascular physiology and cerebral pathology, meticulous planning, and administration of titrated anesthetics to maintain both cardiovascular and cerebrovascular homeostasis are important for the successful outcome. A multidisciplinary approach involving the neurosurgeon, neuroanesthesiologist, cardiologist, and the neurointensivist is needed for a successful outcome.

\section{Funding}

None.

\section{Conflict of Interest}

None declared.

\section{Note}

This case report has not been submitted elsewhere for publication or presented at a meeting.

\section{Author's Contributions}

All authors made material contributions to the handling of this case and to the intellectual content of this article.

\section{References}

1 Sumpelmann R, Osthaus WA. The paediatric cardiac patient presenting for noncardiac surgery. Curr Opin Anaesthesiol. 2007;20(3):216-220

2 White CM, Peyton MJ. Anaesthetic management of children with congenital heart disease for non-cardiac surgery. Contin Educ Anaesth Crit Care Pain 2012;12(1):17-22

3 Dilesh K, Cheran K, Kumar GG, Chandy IP. Anaesthetic management of tetralogy of Fallot coming for noncardiac surgery: a case report. J Evol Med Dental Sci 2015;4(23):4029-4032

4 Rafique NB, Hamid M. Anaesthetic management of craniotomy for intracranial lesion in a child with uncorrected tetralogy of Fallot. J Pak Med Assoc 2013;63(1):123-125

5 Marulasiddappa V, Raghavavendra BS. Anesthesia for a rare case of uncorrected pentalogy of Fallot undergoing craniotomy and drainage of brain abscess. J Clin Diagn Res 2015;9(7):UD01-UD02

6 Siriapisith T, Wasinrat J, Tresukosol D. Uncorrected pink tetralogy of Fallot in an adult patient: incidental CT findings. J Cardiovasc Comput Tomogr 2010;4(1):58-61 